\title{
Fabrication of Ultrafine Carbon Fibers Possessing a Nanoporous Structure from Electrospun Polyvinyl Alcohol Fibers Containing Silica Nanoparticles
}

\author{
Koichi Sawada, Shinji Sakai, and Masahito Taya \\ Division of Chemical Engineering, Department of Materials Engineering Science, Graduate School of Engineering Science, \\ Osaka University, 1-3 Machikaneyama-cho, Toyonaka, Osaka 560-8531, Japan
}

Correspondence should be addressed to Shinji Sakai; sakai@cheng.es.osaka-u.ac.jp and Masahito Taya; taya@cheng.es.osaka-u.ac.jp Received 25 February 2014; Revised 2 May 2014; Accepted 3 May 2014; Published 16 June 2014

Academic Editor: Ruigang Liu

Copyright (C) 2014 Koichi Sawada et al. This is an open access article distributed under the Creative Commons Attribution License, which permits unrestricted use, distribution, and reproduction in any medium, provided the original work is properly cited.

\begin{abstract}
Ultrafine carbon fibers with a nanoporous structure were fabricated by the template method using silica nanoparticles (NPs) embedded in fibers of approximate diameter $500 \mathrm{~nm}$, electrospun from an aqueous solution of polyvinyl alcohol, $\mathrm{CoCl}{ }_{2}$, silica $\mathrm{NPs}$, and $\mathrm{N}, \mathrm{N}$-dimethylformamide. Black, conductive fibers were obtained by heat treatment in air and a chemical vapor deposition reaction under methanol vapor for more than $5 \mathrm{~h}$. Transmission electron microscopy (TEM) demonstrated that the fabricated fibers after silica removal had a porous structure originating from $15 \mathrm{~nm}$ diameter silica NPs. Energy dispersive X-ray analysis combined with TEM confirmed the removal of silica from the fibers by $\mathrm{NaOH}$ treatment at $80^{\circ} \mathrm{C}$. Total surface area and total pore volume of the fibers after silica removal, determined by nitrogen adsorption measurement, were $318 \mathrm{~m}^{2} / \mathrm{g}$ and $1.67 \mathrm{~cm}^{3} / \mathrm{g}$, respectively. The sheet resistivities of the fabricated fibers were 35.1-477 $\Omega / \square$, which were relatively high, compared with that reported for polyacrylonitrilebased fibers carbonized at $800^{\circ} \mathrm{C}$. D and $\mathrm{G}$ bands detected in the Raman spectrum of the NaOH-treated fibers showed that the prepared carbon fibers were more crystalline than natural carbonaceous materials.
\end{abstract}

\section{Introduction}

Carbon materials have attractive properties, such as surface hydrophobicity, chemical inertness, large surface area to volume ratios, and thermal stability. These properties enable their use in various applications, including catalysts [1], energy devices [2], sensors [3], and water and air cleaning elements $[4,5]$. Recently, ultrafine carbon fibers fabricated from electrospun fibers have attracted great interest because they can be obtained as nonwoven fabrics consisting of continuous fibers with diameters ranging from several hundred $\mathrm{nm}$ to sub $\mu \mathrm{m}$ and such fabrics show high porosity and interconnectivity [6]. Ultrafine carbon fibers have been fabricated by carbonization of electrospun fibers made from carbon precursors such as polyacrylonitrile (PAN) and pitch [6].

Much effort has been given to control the structure, texture, and conductivity of fibers to expand the availability of the materials [6]. Amongst the properties of fibrous materials, the pore structure plays a key role in applications. However, the conventional electrospinning process only generates solid ultrafine fibers, without pores. Therefore, posttreatment methods have been developed to create desirable pores in the carbon fibers $[7,8]$. For this purpose, two processes have been reported. One is the treatment of carbon fibers with steam or carbon dioxide at $700-1000^{\circ} \mathrm{C}$, a so-called "activation" process [8]. The other is to induce phase separation using a hard or soft template. Kim et al. fabricated porous PANbased carbon fibers by phase separation. Porous carbon fibers were prepared via electrospinning of PAN and poly(methyl methacrylate) (PMMA), followed by carbonization with decomposition of PMMA [9]. In a recent report, Liu et al. fabricated porous carbon fibers by phase separation via electrospinning of PAN and $\mathrm{CaCO}_{3}$ nanoparticles (NPs) and subsequent carbonization, followed by acid treatment to remove the $\mathrm{CaCO}_{3}$ template. The carbon fibers possessed a nanoporous structure, resulting in a high surface area and pore volume. These characteristics were reported to play a key 
role in a catalytic application and to be potentially useful in other applications [10].

In the current study, the fabrication of carbon fibers with a controlled nanoporous structure is proposed by combining a chemical vapor deposition (CVD) reaction and phase separation using electrospun poly(vinyl alcohol) (PVA) fibers containing $15 \mathrm{~nm}$ silica NPs as pore templates. Figure 1 illustrates the stepwise procedure proposed in this study to prepare nanoporous carbon fibers, which includes the treatments of electrospun fibers with heat and CVD and removal of silica NPs. The fibers are electrospun from a solution composed of PVA, $\mathrm{CoCl}_{2}$, silica NPs, and N,N-dimethylformamide (DMF) as a cosolvent that facilitates electrospinning. Cobalt is known to catalyze carbon deposition during the CVD reaction [11]. In the present study, a cobalt compound was added to the electrospinning solution to facilitate carbon deposition inside the fibers, for maintaining the continuous nanofibrous structure after removal of the silica NPs. Heat treatment produces a fiber preparation containing cobalt and silica NPs. Subsequent removal of the silica NPs by $\mathrm{NaOH}$ endows the resultant carbon fibers with a nanoporous structure.

\section{Materials and Methods}

2.1. Materials. PVA (MW: 146,000-186,000 Da) was purchased from Polysciences, Inc. (Warrington, PA, USA) and $\mathrm{CoCl}_{2} \cdot 6 \mathrm{H}_{2} \mathrm{O}$, DMF, and methanol were products from Wako Pure Chemical Industries Ltd. (Osaka, Japan). Colloidal silica (trade name: Snowtex), a sol of $30 \mathrm{wt} \%$ silica NPs with an average diameter of $15 \mathrm{~nm}$, was provided by Nissan Chemical Industries Ltd. (Tokyo, Japan).

\subsection{Electrospinning of PVA/CoCl $/$ Silica NP Mixture Solution.} An aqueous solution of $15 \mathrm{wt} \%$ PVA was prepared by autoclaving a suspension of PVA powder in distilled water at $120^{\circ} \mathrm{C}$ for $20 \mathrm{~min}$. An aqueous solution of $1 \mathrm{wt} \% \mathrm{CoCl}_{2} \cdot 6 \mathrm{H}_{2} \mathrm{O}$ $(3.9 \mathrm{~g})$ was added dropwise to the colloidal silica sol $(8.4 \mathrm{~g})$ under vigorous stirring using a magnetic stirrer. This solution was mixed with the PVA solution ( $8.5 \mathrm{~g})$ and DMF $(1.7 \mathrm{~g})$ and then electrospun at a tip-to-collector distance of $15 \mathrm{~cm}$, with a solution flow rate of $2.0 \mathrm{~mL} / \mathrm{min}$ and applied voltage of $20 \mathrm{kV}$.

2.3. Formation of Nanoporous Structure by Template Method. The electrospun fibers were calcined at $500^{\circ} \mathrm{C}$ under air flow for $5 \mathrm{~h}$ after elevating the temperature at $5^{\circ} \mathrm{C} / \mathrm{min}$. Subsequently, the resultant fibers were subjected to CVD reaction in a quartz tube furnace $(60 \mathrm{~cm}$ in length). Methanol vapor was delivered by bubbling nitrogen gas through a glass trap containing pure methanol at $200 \mathrm{~cm}^{3} / \mathrm{min}$ and ambient temperature. The methanol/nitrogen gas mixture was then introduced into the furnace and the CVD reaction was performed at $600^{\circ} \mathrm{C}$ for the prescribed period. Finally, the silica NPs were removed to form a nanoporous structure in the carbon fibers by soaking the fibers in a $10 \mathrm{wt} \% \mathrm{NaOH}$ aqueous solution for $24 \mathrm{~h}$ at $80^{\circ} \mathrm{C}$. After treatment, the fibers were rinsed with a large amount of distilled water and lyophilized.
2.4. Morphological Characterization by TEM-EDX. Morphologies and element mapping of the electrospun fibers were characterized with a transmission electron microscopeenergy dispersive X-ray (TEM-EDX) instrument (H800 EDX, Hitachi Co., Tokyo, Japan) operated at $200 \mathrm{kV}$. The fibers were dispersed in water by sonication and deposited on a TEM copper grid.

2.5. Pore Structural Characterization. The pore structure of the fibers was investigated by measuring the nitrogen adsorption/desorption isotherms at $-196^{\circ} \mathrm{C}$ with an automatic volumetric sorption analyzer (Autosorb-1, Quantachrome Co., Boynton Beach, FA, USA). The total surface area $\left(S_{\mathrm{BET}}\right)$ and pore volume $\left(V_{\text {total }}\right)$ were calculated by the BrunauerEmmett-Teller (BET) method and the Brunauer-JoynerHalenda $(\mathrm{BJH})$ method, respectively.

2.6. Sheet Resistivity Measurement. Sheet resistivity of the fibers was evaluated by a four-point probe resistivity measurement with a resistivity meter (RT-70V/RG-5, Napson Co., Chiba, Japan). The fibrous mats were cut and shaped into rectangles that were $1 \mathrm{~cm}$ square on each side, with an average thickness of $35 \mu \mathrm{m}$, and placed on a glass substrate.

2.7. Raman Spectroscopy Measurement. Raman spectroscopy was carried out to evaluate the quality and crystallinity of carbon fibers using a confocal Raman microscope (LabRAM HR-800, Horiba, Ltd., Kyoto, Japan) at a wavelength of $532 \mathrm{~nm}$.

\section{Results and Discussion}

3.1. Electrospinning and TEM-EDX Characterization. Ultrafine PVA fibers of about $500 \mathrm{~nm}$ in diameter containing $\mathrm{CoCl}_{2}$ and silica NPs were obtained by electrospinning. The white color of fibers as spun (Figure 2(a)) apparently became light blue after calcination in air at $500^{\circ} \mathrm{C}$ for $5 \mathrm{~h}$ (Figure $2(\mathrm{~b})$ ). From the TEM observations of fibers as spun and after calcination, it was found that the electron transparency inside the fibers increased somewhat after calcination and the presence of silica particles became more distinct (Figures 2(a) and 2(b)). This result indicates that the calcination treatment yielded fibers predominantly containing silica NPs (Figure 2(b)). As seen in Figures 2(b) and 2(c), no significant structural difference was observed by TEM between the fibers before and after the CVD reaction. However, a color change from white to black after the CVD reaction was obvious, which indicates the deposition of carbon in/on the fibers (Figure 2(c)). A black mat was obtained even after silica removal with $\mathrm{NaOH}$ treatment for $24 \mathrm{~h}$. Electron transparency of the fibers was significantly increased after the $\mathrm{NaOH}$ treatment (Figures 2(c) and 2(d)). This result indicates that after the $\mathrm{NaOH}$ treatment, the fibers had a nanoporous structure originating from the silica NPs.

Next, the silica removal was confirmed by an EDX spectrometer equipped with TEM. Figures 3(a)-3(f) show scanning transmission electron microscopic (STEM) images and the results of element mapping for Si and Co. As seen 


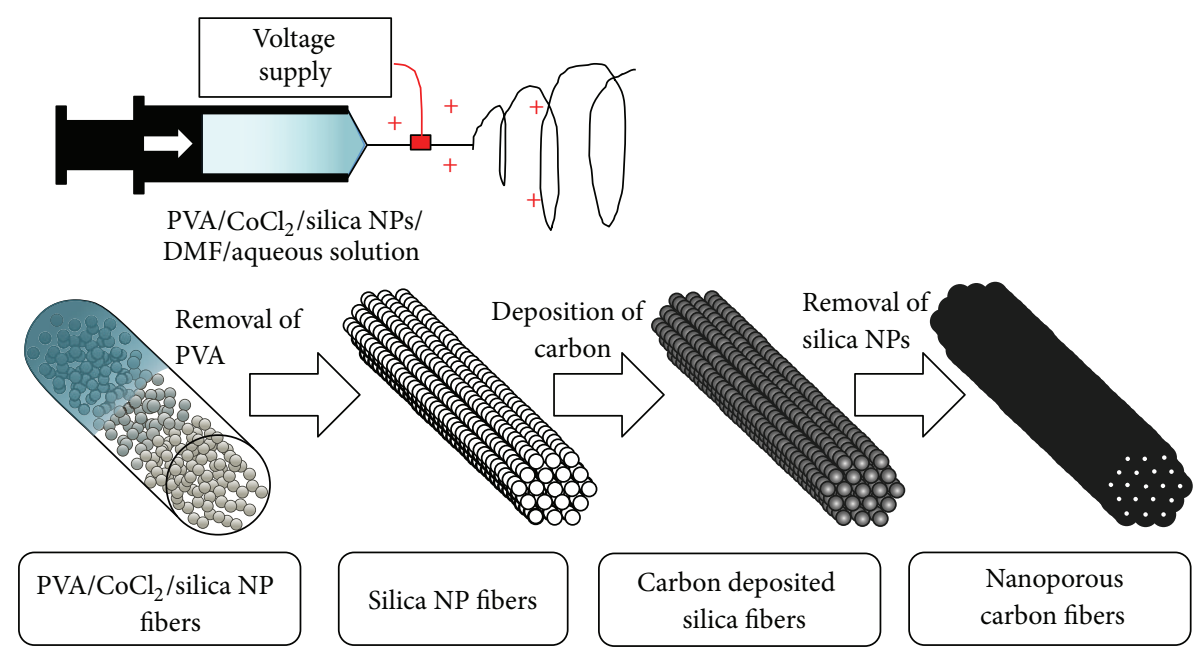

FIGURE 1: Schematic drawing of the stepwise procedure for fabrication of nanoporous carbon fibers by combined electrospinning, CVD reaction, and phase separation.

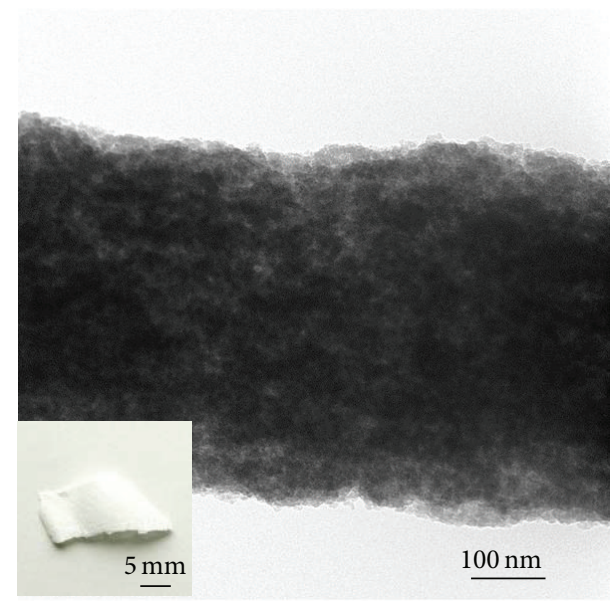

(a)

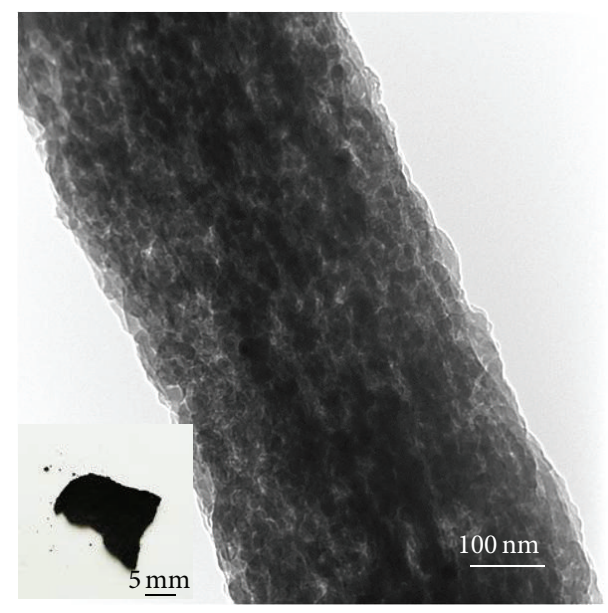

(c)

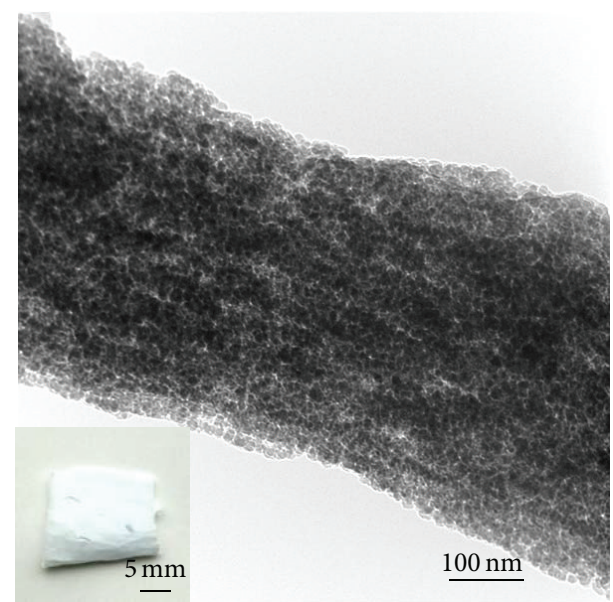

(b)

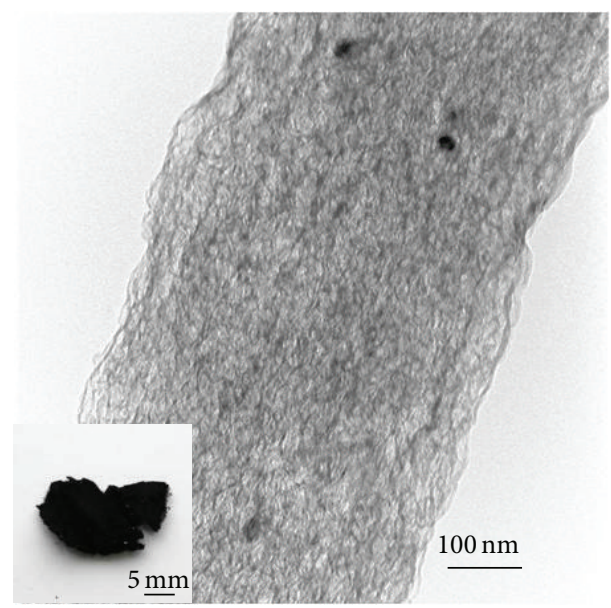

(d)

Figure 2: Photographs and TEM images of the PVA/ $\mathrm{CoCl}_{2} /$ silica NP fibers as spun (a), after heat treatment at $500^{\circ} \mathrm{C}$ for $5 \mathrm{~h}$ in air $(\mathrm{b})$, after $\mathrm{CVD}$ reaction at $600^{\circ} \mathrm{C}$ for $24 \mathrm{~h}(\mathrm{c})$, and after $\mathrm{NaOH}$ treatment at $80^{\circ} \mathrm{C}$ for $24 \mathrm{~h}$ (d). 


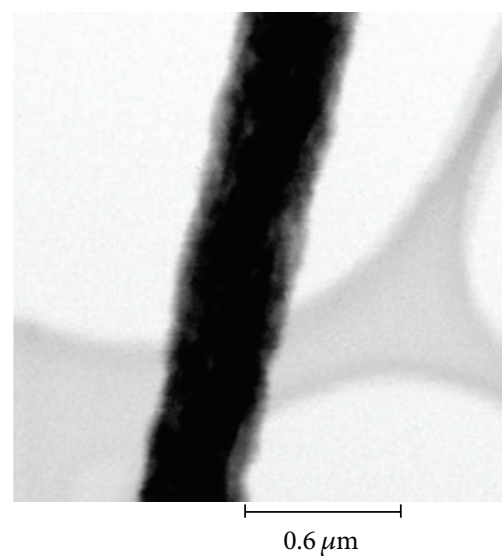

(a)

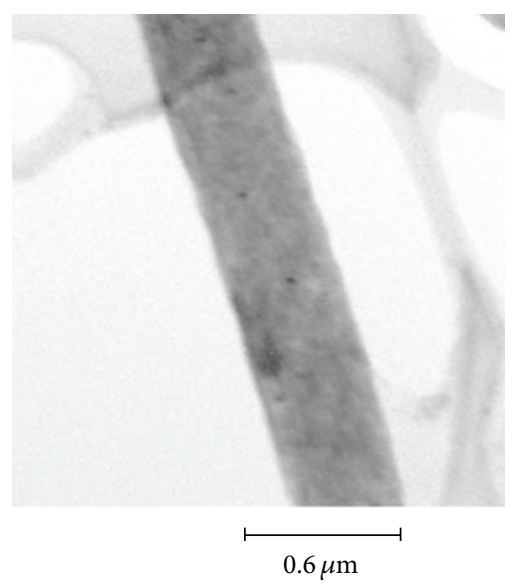

(d)

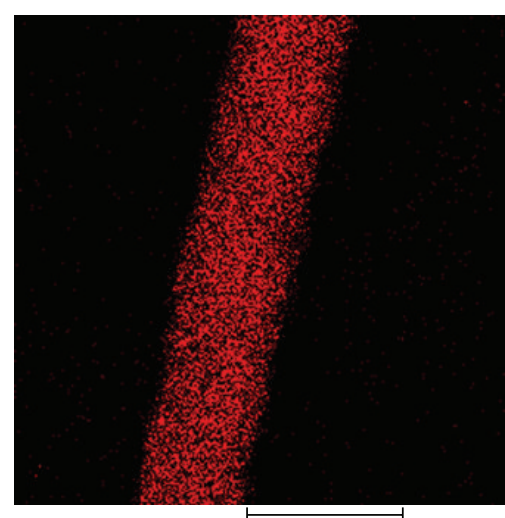

$0.6 \mu \mathrm{m}$

(b)

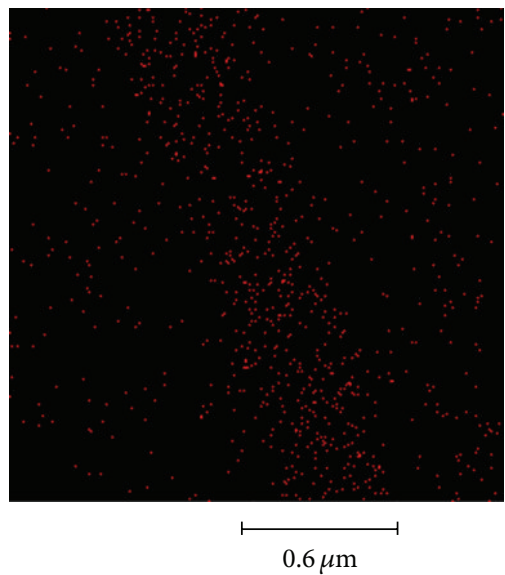

(e)

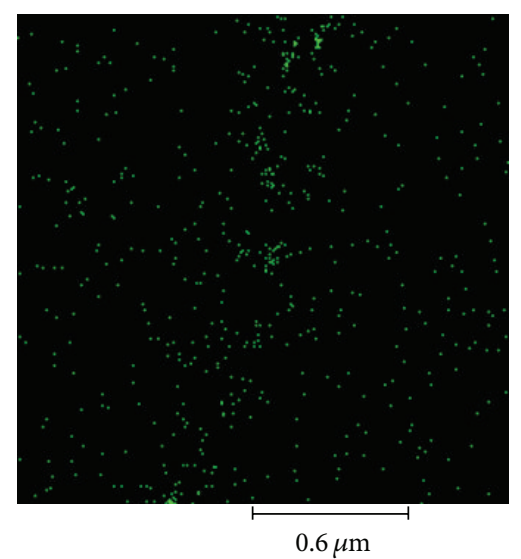

(c)

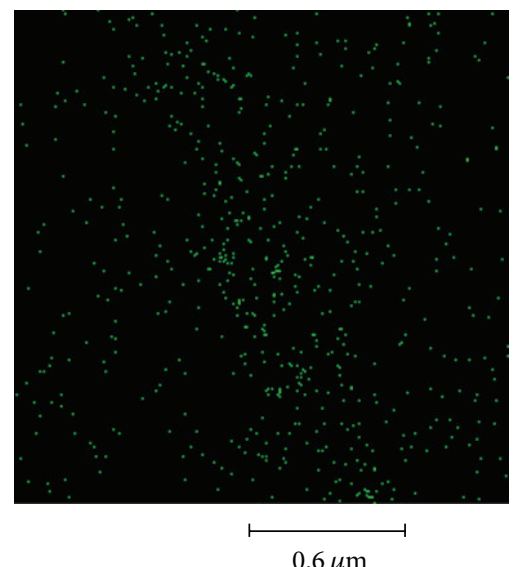

(f)

FIGURE 3: STEM images ( $a$ and d) and element mapping by EDX spectroscopy of Si (b and e) and Co (c and f) in the fibers before and after $\mathrm{NaOH}$ treatment at $80^{\circ} \mathrm{C}$ for $24 \mathrm{~h}$, respectively.

in Figures 3(a) and 3(b), it was found that after the CVD reaction, the fibers contained a large amount of silica NPs. From an appreciable decrease in the Si signals, the silica NPs were shown to have been substantially removed by the $\mathrm{NaOH}$ treatment (Figures 3(b) and 3(e)). As shown in Figures 3(c) and $3(\mathrm{f})$, conversely, the signals for Co were too weak to detect its location or any difference after the $\mathrm{NaOH}$ treatment.

3.2. Pore Structural Characterization. The pore structures of the carbon fibers were determined by the nitrogen adsorption/desorption method. The isotherm observed for the fibers after the $\mathrm{NaOH}$ treatment had a type-H1 hysteresis loop (Figure 4(a)) [12], which was not observed for the fibers before the treatment, while the capillary condensation occurred at high relative pressures $\left(P / P_{0}=0.85-0.97\right)$. Additionally, from the corresponding pore size distributions of the fibers calculated by the $\mathrm{BJH}$ method, it was shown that the $\mathrm{NaOH}$ treatment increased mainly the quantity of mesopores $(2-50 \mathrm{~nm})$ and partially the quantity of macropores $(>50 \mathrm{~nm})$ in the fibers (Figure 4(b)). Table 1 summarizes the BET surface area and pore volume distributions of the fibers after the CVD and $\mathrm{NaOH}$ treatment. The BET surface area of the fibers increased approximately 4 times after the $\mathrm{NaOH}$ treatment. Notably, the mesopore volume, in particular, greatly increased from 0.26 to $1.33 \mathrm{~cm}^{3} / \mathrm{g}$ through the $\mathrm{NaOH}$ treatment. These results indicate that the $15 \mathrm{~nm}$ silica NPs loaded into the fibers acted as templates for pores in the resultant fibers. The total pore volume also increased from 0.37 to $1.67 \mathrm{~cm}^{3} / \mathrm{g}$, which is comparable with that of carbon aerogels $[13,14]$ and larger than that of carbon nanotubes synthesized by acetylene decomposition on cobalt-supported silica [14]. The highly porous fibrous structure may be useful in applications as catalyst supports and water cleaning, such as oil spill cleanup [10].

\subsection{Effect of CVD Reaction Time on Sheet Resistivity. The} sheet resistivity of the fibers was measured to evaluate the amount of carbon deposition, as influenced by CVD reaction time. As shown in Figure 5, for $15 \mathrm{~min}$ reaction, the fibers displayed high resistivity, acting as insulators. By prolonging the reaction time from $15 \mathrm{~min}$ to $1 \mathrm{~h}$, the obtained fibers became conductive, with a sheet resistivity of $477 \pm 66.4 \Omega / \square$, and further reaction for $5 \mathrm{~h}$ lowered the resistivity to $56.3 \pm$ $1.47 \Omega / \square$. Finally, the sheet resistivity of the fibers, after $24 \mathrm{~h}$ 


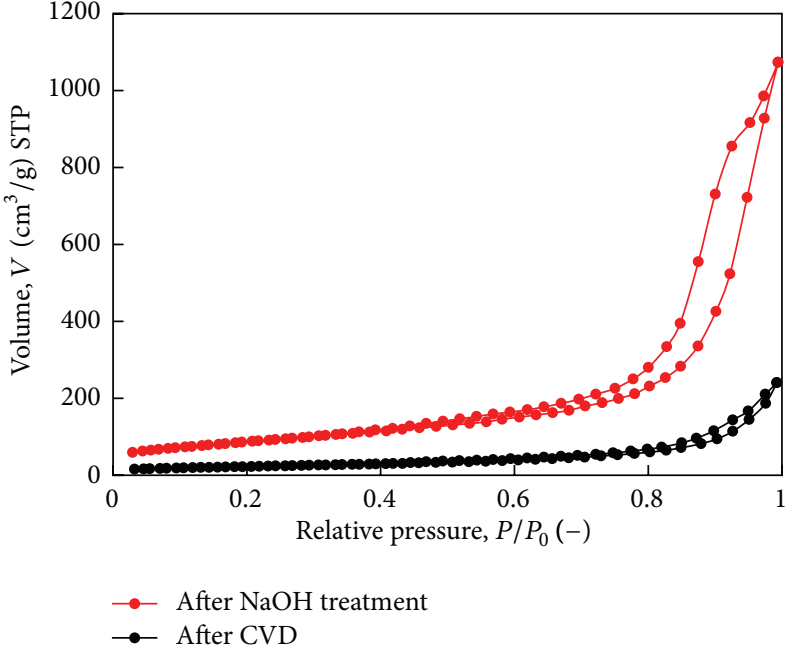

(a)

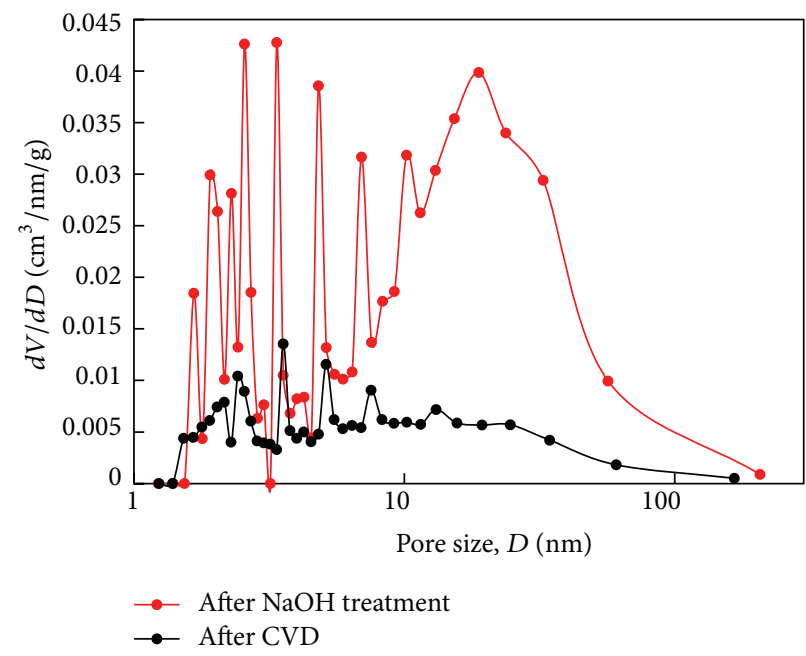

(b)

FIGURE 4: Nitrogen adsorption/desorption isotherms (a) and pore size distributions (b) for the fibers after CVD reaction at $600^{\circ} \mathrm{C}$ for $24 \mathrm{~h}$ and after $\mathrm{NaOH}$ treatment at $80^{\circ} \mathrm{C}$ for $24 \mathrm{~h}$. STP: standard temperature and pressure $\left(1 \mathrm{~atm}, 0^{\circ} \mathrm{C}\right)$.

TABLE 1: Surface area and pore volume distributions of the fibers.

\begin{tabular}{lccccc}
\hline & $\begin{array}{c}S_{\mathrm{BET}} \\
\left(\mathrm{m}^{2} / \mathrm{g}\right)\end{array}$ & $\begin{array}{c}V_{\text {micro }}{ }^{\mathrm{a}} \\
\left(\mathrm{cm}^{3} / \mathrm{g}\right)\end{array}$ & $\begin{array}{c}V_{\text {meso }}{ }^{\mathrm{b}} \\
\left(\mathrm{cm}^{3} / \mathrm{g}\right)\end{array}$ & $\begin{array}{c}V_{\text {macro }}{ }^{\mathrm{c}} \\
\left(\mathrm{cm}^{3} / \mathrm{g}\right)\end{array}$ & $\begin{array}{c}V_{\text {total }} \\
\left(\mathrm{cm}^{3} / \mathrm{g}\right)\end{array}$ \\
\hline $\begin{array}{l}\text { Fibers after CVD } \\
\text { Fibers after } \mathrm{NaOH}\end{array}$ & 82 & $\mathrm{ND}$ & 0.26 & 0.11 & 0.37 \\
treatment & 318 & 0.02 & 1.33 & 0.32 & 1.67 \\
\hline
\end{tabular}

${ }^{\mathrm{a}}$ Volume of micropores $(<2 \mathrm{~nm})$. ${ }^{\mathrm{b}}$ Volume of mesopores $(2-50 \mathrm{~nm})$.

${ }^{c}$ Volume of macropore (>50 nm). ND: not detectable.

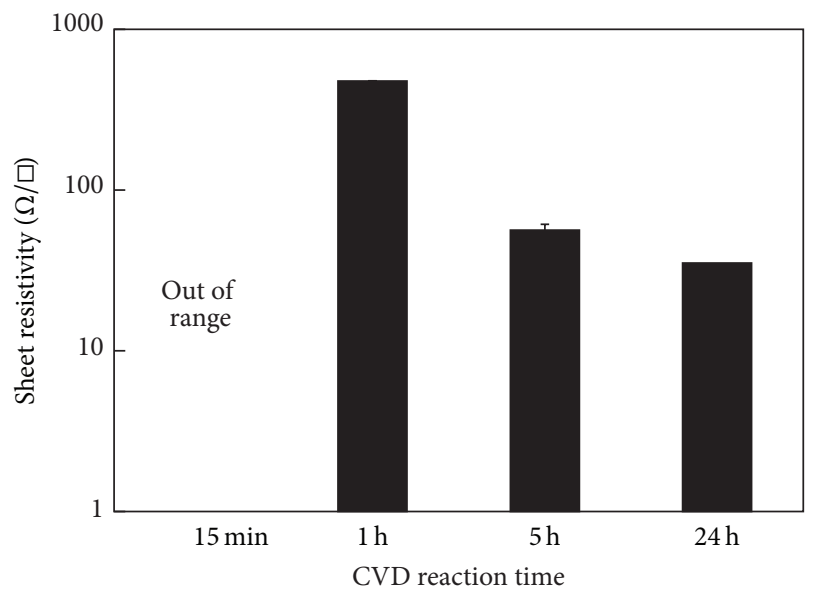

Figure 5: Effect of CVD reaction time on sheet resistivity of the fibers after CVD reaction at $600^{\circ} \mathrm{C}$ and $\mathrm{NaOH}$ treatment at $80^{\circ} \mathrm{C}$ for $24 \mathrm{~h}$.

CVD, was $35.1 \pm 4.82 \Omega / \square$, which was similar to that of the fibers after $5 \mathrm{~h} \mathrm{CVD}$ reaction. Considered together with the TEM image of the fibers that had undergone the CVD reaction (Figure $2(\mathrm{c})$ ), these results indicate that $5 \mathrm{~h} C V D$ reaction was sufficient to accumulate carbon deposits in/on the fibers under the conditions examined in the current study. Although these values of sheet resistivity are higher than those of carbonized PAN-based carbon fibers reported in the literature [6], it is difficult to compare sheet resistivity because of differences in material properties such as pore size and porosity. As the preparation process was not fully optimized in the current study, there is a possibility that sheet resistivity can be decreased by tailoring the electrospun fibers and CVD conditions.

3.4. Raman Spectroscopic Analysis. Raman spectroscopy is a powerful tool used to evaluate the quality and degree of crystallinity of vapor-grown carbon materials [12]. Figure 6 shows the Raman spectrum of fibers fabricated by the CVD reaction for $24 \mathrm{~h}$ and subsequent $\mathrm{NaOH}$ treatment. The pair of bands at 1358 and $1581 \mathrm{~cm}^{-1}$, designating the $\mathrm{D}$ and $\mathrm{G}$ bands, respectively, are the most diagnostically relevant features. The $\mathrm{D} / \mathrm{G}$ intensity, which strongly depends on the structure of the carbon, was 1.02 for the prepared fibers. This result indicates that the carbon deposits in/on the fabricated fibers possessed a low degree of crystallinity, although they had a more crystalline nature than charcoal and coke [12].

\section{Conclusions}

Ultrafine carbon fibers with a nanoporous structure were fabricated by a template method using silica NP-containing fibers, electrospun from a PVA-based aqueous solution. Black, conductive fibers were obtained by the CVD reaction under methanol vapor for a minimum of $5 \mathrm{~h}$. TEM observation demonstrated that, after silica removal, the fabricated fibers had a structure originating from the silica NPs. The nitrogen adsorption/desorption method showed that the carbon fibers mainly contained mesopores $(2-50 \mathrm{~nm})$ and 


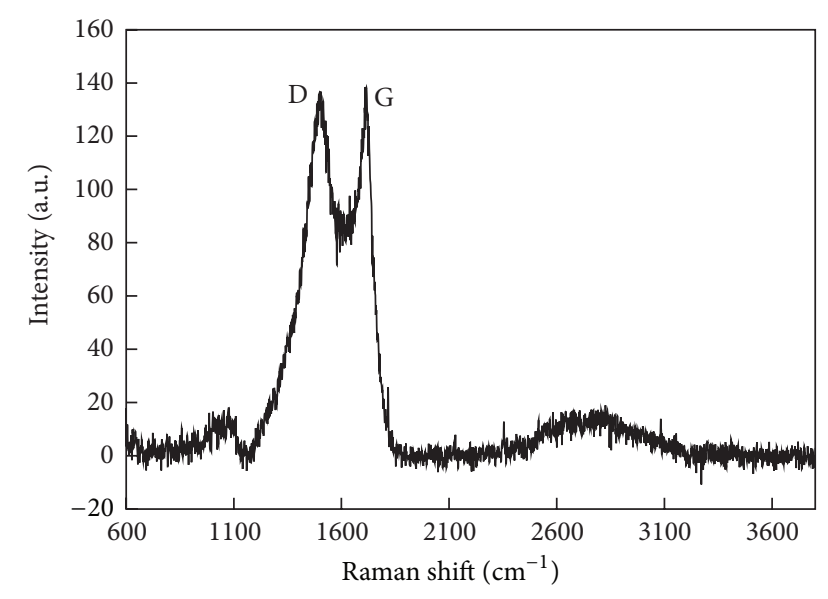

FIgURE 6: Raman spectrum of the fibers after CVD reaction at $600^{\circ} \mathrm{C}$ for $24 \mathrm{~h}$.

macropores $(>50 \mathrm{~nm})$. The total surface area and total pore volume of the fibers after silica removal were $318 \mathrm{~m}^{2} / \mathrm{g}$ and $1.67 \mathrm{~cm}^{3} / \mathrm{g}$, respectively. EDX analysis equipped with TEM confirmed the removal of silica from the fibers by the $\mathrm{NaOH}$ treatment at $80^{\circ} \mathrm{C}$. The sheet resistivity of the fabricated fibers was relatively high compared with that reported for PAN-based fibers carbonized at $800^{\circ} \mathrm{C}$. Raman spectroscopy showed that the prepared carbon fibers were more crystalline than natural carbonaceous materials.

\section{Conflict of Interests}

The authors declare that there is no conflict of interests regarding the publication of this paper.

\section{Acknowledgments}

The authors express their appreciation to Professor H. Yasuda and Dr. T. Sakata, Research Center for Ultra-High Voltage Electron Microscopy, Osaka University, for kind assistance in TEM experiments. The authors also express their appreciation to Dr. N. Nishiyama and Drs. H. Umakoshi and K. Suga, Graduate School of Engineering Science, Osaka University, for giving the facilities for nitrogen adsorption/desorption isotherm measurements and Raman spectroscopy analysis, respectively. This study was in part supported by the Kansai Research Foundation for Technology Promotion, Japan. One of the authors (Koichi Sawada) is grateful for financial support from a Grant-in-Aid for JSPS Fellows (no. 25.1614).

\section{References}

[1] F. Rodríguez-Reinoso, "The role of carbon materials in heterogeneous catalysis," Carbon, vol. 36, no. 3, pp. 159-175, 1998.

[2] G. S. Chai, S. B. Yoon, J.-S. Yu, J.-H. Choi, and Y.-E. Sung, "Ordered porous carbons with tunable pore sizes as catalyst supports in direct methanol fuel cell," Journal of Physical Chemistry B, vol. 108, no. 22, pp. 7074-7079, 2004.
[3] S. Sotiropoulou, V. Gavalas, V. Vamvakaki, and N. A. Chaniotakis, "Novel carbon materials in biosensor systems," Biosensors and Bioelectronics, vol. 18, no. 2-3, pp. 211-215, 2002.

[4] C. Lu, Y.-L. Chung, and K.-F. Chang, "Adsorption of trihalomethanes from water with carbon nanotubes," Water Research, vol. 39, no. 6, pp. 1183-1189, 2005.

[5] C. H. Ao and S. C. Lee, "Indoor air purification by photocatalyst $\mathrm{TiO}_{2}$ immobilized on an activated carbon filter installed in an air cleaner," Chemical Engineering Science, vol. 60, no. 1, pp. $103-$ 109, 2005.

[6] M. Inagaki, Y. Yang, and F. Kang, "Carbon nanofibers prepared via electrospinning," Advanced Materials, vol. 24, no. 19, pp. 2547-2566, 2012.

[7] Y. Yang, A. Centrone, L. Chen, F. Simeon, T. Alan Hatton, and G. C. Rutledge, "Highly porous electrospun polyvinylidene fluoride (PVDF)-based carbon fiber," Carbon, vol. 49, no. 11, pp. 3395-3403, 2011.

[8] N. N. Bui, B. H. Kim, K. S. Yang, M. E. D. Cruz, and J. P. Ferraris, "Activated carbon fibers from electrospinning of polyacrylonitrile/pitch blends," Carbon, vol. 47, pp. 2528-2555, 2009.

[9] C. Kim, Y. I. Jeong, B. T. N. Ngoc et al., "Synthesis and characterization of porous carbon nanofibers with hollow cores through the thermal treatment of electrospun copolymeric nanofiber webs," Small, vol. 3, no. 1, pp. 91-95, 2007.

[10] H. Liu, C. Y. Cao, F. F. Wei et al., "Fabrication of macroporous/ mesoporous carbon nanofiber using $\mathrm{CaCO}_{3}$ nanoparticles as dual purpose template and its application as catalyst support," The Journal of Physical Chemistry C, vol. 117, pp. 21426-21432, 2013.

[11] Z. P. Huang, D. Z. Wang, J. G. Wen, M. Sennett, H. Gibson, and Z. F. Ren, "Effect of nickel, iron and cobalt on growth of aligned carbon nanotubes," Applied Physics A: Materials Science and Processing, vol. 74, no. 3, pp. 387-391, 2002.

[12] D. Zhao, J. Feng, Q. Huo et al., "Triblock copolymer syntheses of mesoporous silica with periodic 50 to 300 angstrom pores," Science, vol. 279, no. 5350, pp. 548-552, 1998.

[13] Y. Hanzawa, H. Hatori, N. Yoshizawa, and Y. Yamada, "Structural changes in carbon aerogels with high temperature treatment," Carbon, vol. 40, no. 4, pp. 575-581, 2002.

[14] E. Frackowiak and F. Béguin, "Carbon materials for the electrochemical storage of energy in capacitors," Carbon, vol. 39, no. 6, pp. 937-950, 2001. 

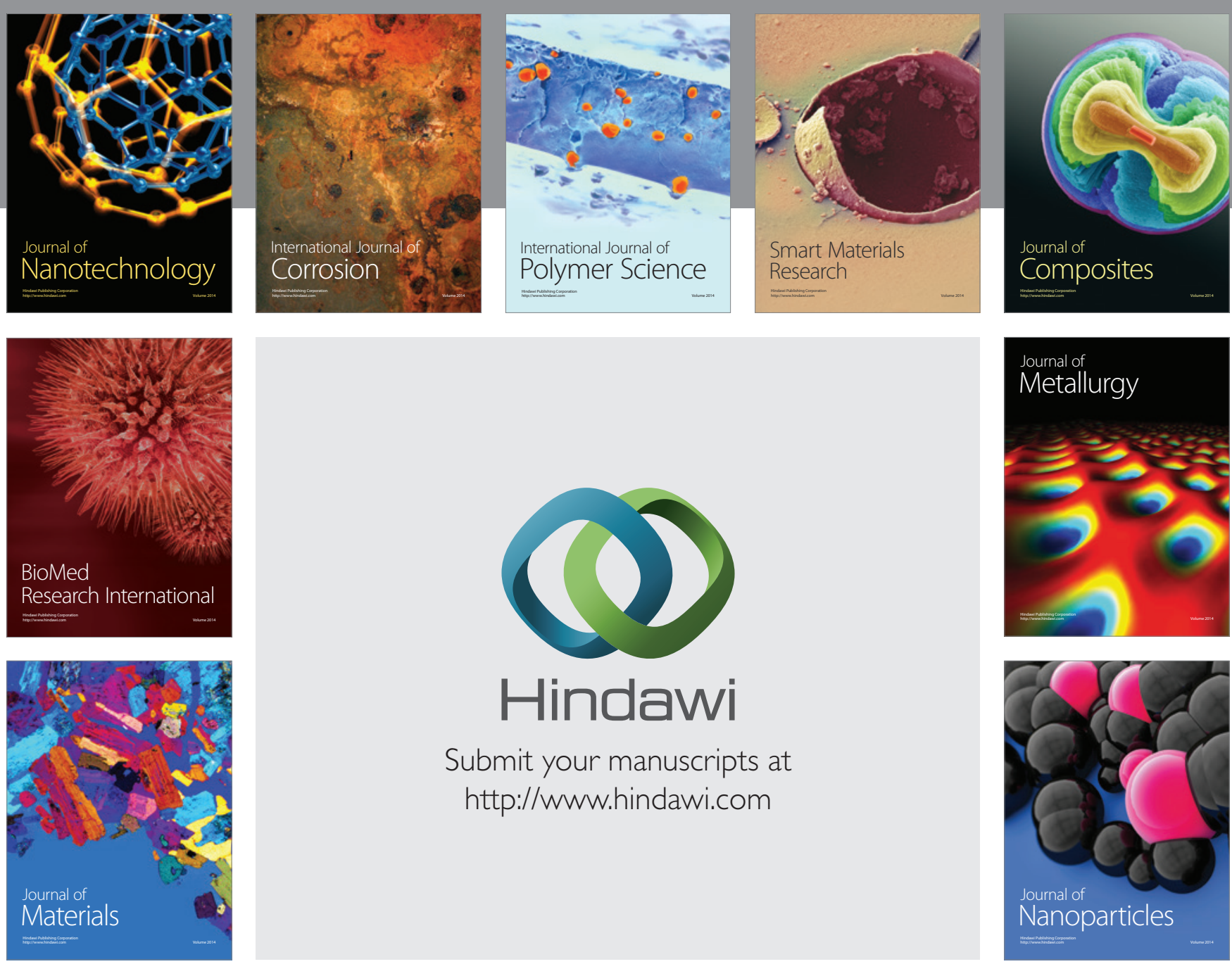

Submit your manuscripts at http://www.hindawi.com
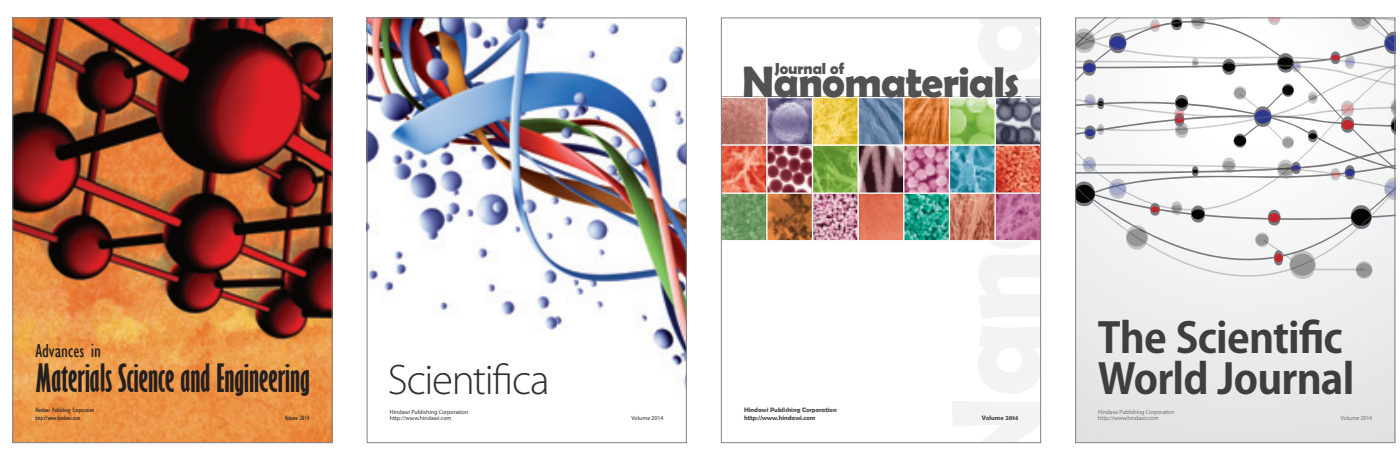

\section{The Scientific World Journal}
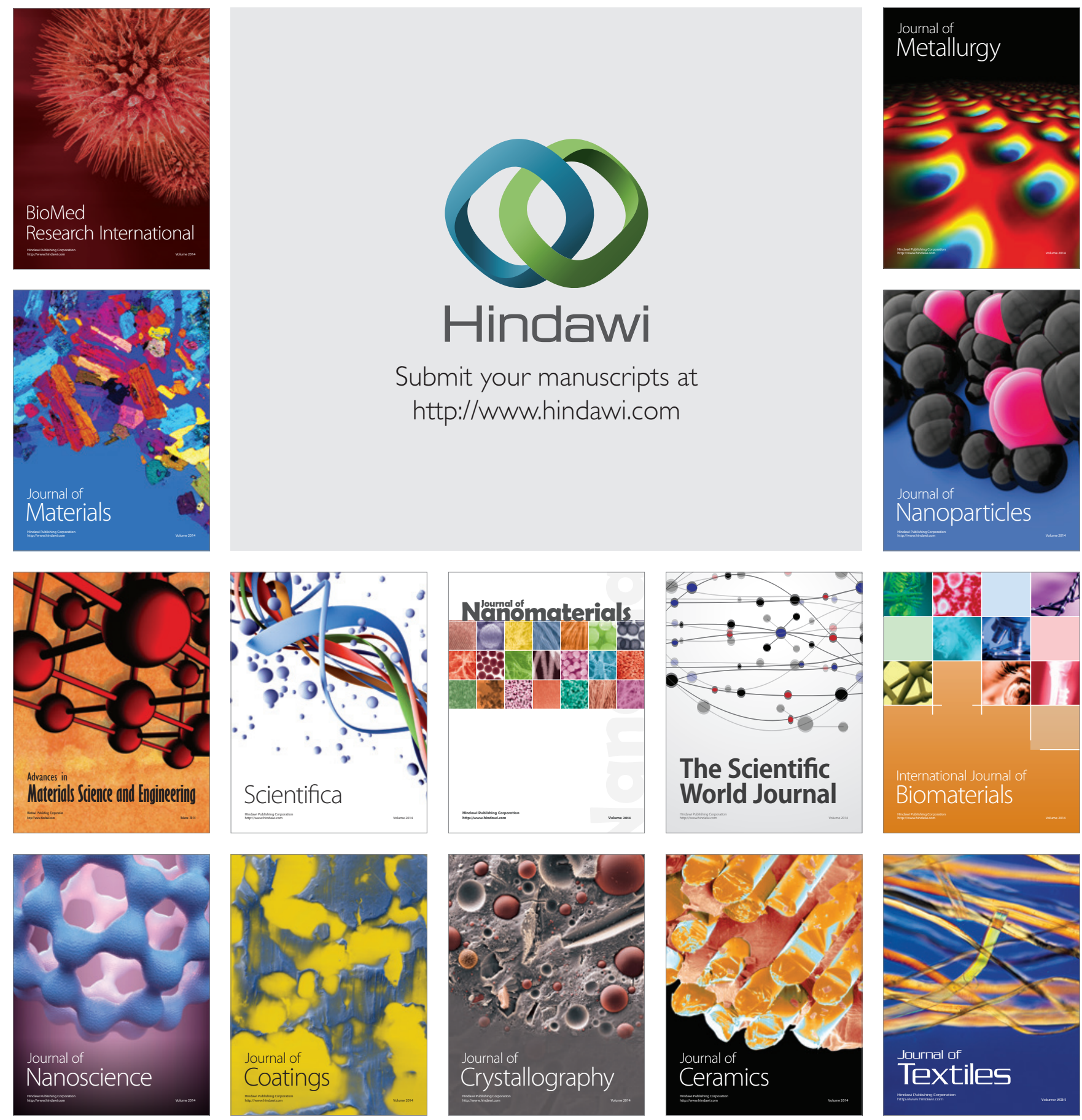